Commander P. C. H. Clissold comments:

My queries admittedly dealt with details and one of my reasons for putting them was to stimulate discussion of the whole subject of Rule of the Road at this time-within a year of the International Convention on Safety of Life at Sea.

The Rules are certainly based on the principle (even if they do not say so) that the more manœuvrable vessel must give way to the less manœuvrable, and that power-driven vessels of equal manœuvrability, as Captain Hilder says, keep generally to the right. Since 1948 all (sail or steam) vessels not fishing give way to all (sail or steam) vessels fishing. Steam gives way to sail. Vessels not manœuvrable carry special signals to show that they cannot get out of the way of an approaching vessel, which surely implies the duty of approaching vessels to avoid them. The only doubtful case is that of a vessel towing, which I suggested could be clarified if the vessel towed carried two black balls or two red lights. The only exception has come to be when a sailing vessel running free meets a vessel close-hauled. The Rules were formulated chiefly for square-rigged vessels, and with square-rig the one running free could more easily alter course: with fore-and-afters the opposite is the case. Today, logically, the Rule should be reversed, but it might be better to have no special rules for sailing vessels and that they should follow the same rules as steam vessels do when meeting each other or to adopt R.Y.A.'s proposal that a sailing vessel with the wind on the port side should give way to a sailing vessel with the wind on the starboard side, irrespective of whether either of them is close-hauled or running free.

It is to be hoped that when the delegates meet next year they will have had the time and opportunity to study the views of many seamen experienced in navigating different types of vessels: fully-manœuvrable power-driven vessels, tugs, cable ships, fishing craft, yachts, \&c., as to the sufficiency of the present Rules both in content and clarity.

\title{
Aircraft Navigational Errors
}

$$
\text { from Captain J. D. Proctor }
$$

C. S. DURST 1 has tried to discover the frequency distribution of aircraft navigational errors from D. C. Willis's data. ${ }^{2}$ But how reliable are Willis's data for this purpose?

D.R. errors and track-keeping errors are differences between assumed and true positions. Evidence of assumed position is ayailable, but how can true position over the Atlantic ever be discovered accurately? Willis estimated true position by post flight analysis of navigational and meteorological data, but any such analysis must be based on some doubtful assumptions, for instance that compass error or wind was constant between fixes or that the true position.was at the 'middle' of a 'reliable' fix. The analysis must also comprise many delicate judgments, for instance that the true position was at $A$, not $B$, because if it were at $B$ an abnormal wind change must have occurred for which there is only slight evidence.

In these circumstances may not bias easily occur in the post-flight analysis in two ways? May not the analyst (like the navigator) tend to disbelieve and reject 
or reduce the unusual, i.e. very large or very small errors, or unusual combinations of them? May not the many judgments he has to make be biased by his preconceptions or hopes concerning the errors? The navigator may also tend to make and record observations in a slightly biased way, reducing apparent errors.

Is it not possible that these sources of inaccuracy in the measurement of navigational error may considerably alter the shape of the tails of the frequency distribution?

\section{Mr. J. B. Parker comments:}

It is true, as Captain Proctor points out, that post-flight analysis may be a somewhat subjective process. On the other hand, the evaluation of navigational errors by means of a monitoring device of high accuracy in the aircraft would be unsatisfactory. First the amount of data obtained would be extremely scanty, but, more important, the navigator's judgment and the 'operational' nature of the results would probably be prejudiced if he knew that he had a high accuracy monitoring device to fall back on if he were in serious difficulty.

It seems then that post-flight analysis is the only effective way to measure the accuracy of dead reckoning errors in actual operations and the question arises as to how the inaccuracies in determining true position, mentioned by Captain Proctor, will influence the results.

If these inaccuracies are random, and small compared with the navigational errors themselves, the effect will be negligible. The case of consistent biasing, the post-flight analyst tending, perhaps subconsciously, to reject extremely large or very small errors, is more serious and, if the bias existed, the results may be misleading. I can only point to two factors which lead me to believe that the post-flight analysis has been done in a manner as free as possible from bias:

(a) The distribution of errors found was markedly non-Gaussian, the proportion of large errors being higher than would be expected if the Gaussian law operated. This suggests that the large errors referred to by Captain Proctor were in fact not excluded.

(b) A perusal of the observations themselves (a copy of which Captain Willis had the kindness to send me) indicates that the post-flight analyst was not being unreasonably influenced in favour of the navigator.

\section{REFEREN CES}

1 Durst, C. S. (1959). Abnormal errors and aircraft separation over the North Atlantic. This Journal, 12, $4 \mathrm{I}$.

2 Willis, D. C. (1958). Dead reckoning and wind-finding accuracy over the North Atlantic. This Journal, I I, 282.

\section{The Pelorus}

\section{Commander W. E. May, R.N. (National Maritime Museum)}

IN 1854 a bearing plate was invented by Matthew Curling Friend and William Browning to facilitate the taking of bearings where the compass was inconveniently situated for observation. 